\title{
SISTEM INFORMASI PEMESANAN DENGAN PENERAPAN KONSEP ELECTRONIC CUSTOMER RELATION MANAGEMENT BERBASIS WEB
}

\author{
I Dewa Ayu Eka Yuliani ${ }^{1}$ \\ Susanti Margaretha Kuway ${ }^{2}$ \\ STMIK Pontianak; Jl. Merdeka No. 372 Pontianak, 0561-735555 \\ Jurusan Sistem Informasi, STMIK Pontianak, Pontianak \\ Email:dewaayu.ekayuliani@gmail.com, shanty_stmikptk@yahoo.com
}

Diterima: 6 Desember 2016/ Disetujui : 20 Desember 2016

\begin{abstract}
Building customer loyalty at Multi Sport Pontianak requires corporations to create new, innovative, and differentiated products. Quality assurance is one of the most important aspect beside employing technology to provide better information to customers and also better before and after sales services. This research employs research and development method to design E-CRM with sequential Linear and Unified Modelling Language as tools for system modelling. Ordering information system design with E-CRM helps store users to build better customer loyalty with uptodate information and promotion to targeted customer. By listening to customer, better customer loyalty will be achieved. Ecrm provides better understanding of customers with its real time interaction during sales process. This feature enables corporations to build better products and services and in the end creates better customer loyalty.
\end{abstract}

Keywords-E-CRM, waterfall method, UML, ordering information system

\begin{abstract}
ABSTRAK
Kebutuhan membangun loyalitas pelanggan pada toko olahraga Multi Sport di Pontianak mengharuskan perusahaan mampu memberikan kenyamanan kepada pelanggan dengan cara mengedepankan quality assurance, memberikan produk baru yang penuh inovasi dan differensi dengan produk yang ditawarkan perusahaan lain, memberikan perhatian before dan after sales, memanfaatkan teknologi untuk mempermudah pelanggan dalam bertransaksi dan memberikan pelayanan dan informasi yang maksimal kepada pelanggan. Metode penelitian yang digunakan adalah metode penelitian dan pengembangan atau yang lebih dikenal dengan Research and Development (R\&D). Perancangan E-CRM menggunakan metode waterfall dengan model sekuensial linear dan pemodelan sistem menggunakan Unified Modeling Language (UML). Perancangan sistem informasi pemesanan yang berbasiskan konsep E-CRM telah membantu pemilik toko untuk meningkatkan loyalitas pelanggan dengan memberikan fasilitas promosi dan informasi yang up-to-date. Adanya konsep E-CRM memberikan kemudahan bagi pelanggan untuk melakukan pemesanan barang serta pelanggan dapat berkonsultasi dengan pemilik toko terkait dengan harapan dan keinginan pelanggan sehingga menciptakan loyalitas yang tinggi bagi pelanggan.
\end{abstract}

Kata kunci-E-CRM, metode waterfall, UML, sistem informasi pemesanan

\section{PENDAHULUAN}

Alasan yang memungkinkan mengapa pelanggan menjadi lebih loyal terhadap merek pada jasa adalah pengenalan kebutuhan pelanggan sehingga mereka memperoleh kepuasan optimal dari penjual. Peranan karyawan terutama karyawan front-stage juga sangat penting menunjang keberhasilan setiap perusahaan terutama perusahaan yang bergerak di sektor jasa. Alasannya karena karyawan memiliki kemampuan untuk mempengaruhi persepsi pembeli [1]. Konsep kepuasan konsumen merupakan hasil dari keberhasilan penyedia produk memenuhi harapan konsumen dan secara definitif mempengaruhi perubahan sikap, pembelian ulang dan loyalitas [2]. Loyalitas pada 
toko adalah faktor penting dalam kesuksesan perdagangan eceran dan kemampuan toko untuk bertahan. Selain itu pada era pasar moderen saat ini, loyalitas terhadap sebuah toko dapat ditentukan langsung oleh ekspektasi pelanggan terhadap produk dan jasa yang ditawarkan [3]. Mengelola hubungan baik dengan pelanggan merupakan strategi perusahaan dalam rangka meningkatkan loyalitas penggunaan produk/jasa yang ditawarkan oleh perusahaan. Selain dapat meningkatkan pendapatan dalam jangka waktu yang panjang, pelanggan yang loyal dapat membentuk image positif terhadap produk/jasa yang dimiliki perusahaan[4]. Salah satu metode yang dapat digunakan untuk melakukan improvisasi dan peningkatan pelayanan maupun promosi kepada pelanggan adalah dengan yaitu Customer Relationship Management (CRM [5]. Costumer Relationship Management (CRM) merupakan strategi untuk memperoleh, mengkonsolidasi, menganalisa data untuk kemudian digunakan untuk berinteraksi dengan customer dengan demikian akan tercipta suatu pandangan yang komprehensif terhadap customer dan hubungan yang lebih baik dengan customer [6]. Untuk dapat menciptakan loyalitas pelanggan, perusahaan harus mampu memberikan kenyamanan kepada pelanggan dengan cara mengedepankan quality assurance, memberikan produk baru yang penuh inovasi dan differensi dengan produk yang ditawarkan perusahaan lain, memberikan perhatian before dan after sales, memanfaatkan keterampilan karyawan dalam memberikan pelayanan kepada pelanggan, memanfaatkan teknologi untuk mempermudah pelanggan dalam bertransaksi dan memberikan pelayanan dan informasi yang maksimal kepada pelanggan [7]. Dengan menggunakan sistem E-CRM, perusahaan menggunakan konsep yang modern dalam melayani konsumen [8]. Pemanfaatan E-CRM dapat memberikan kemudahan bagi konsumen untuk melakukan kegiatan transaksi bisnis dengan perusahaan, karena dengan adanya E-CRM maka perusahaan dapat lebih mudah menjalin hubungan dengan konsumen agar kegiataannya dapat berjalan baik dan lancar [9].

Toko Multi Sport adalah sebuah perusahaan yang bergerak dibidang penjualan barang untuk kebutuhan peralatan olah raga. Permasalahan yang dihadapi oleh pengelola toko adalah tidak bisa mempertahankan pelanggan mereka untuk tetap membeli barang pada toko Multi Sport. Perusahaan lain yang bergerak dibidang yang sama sudah banyak bermunculan dan itu merupakan tantangan bagi Toko Multi Sport untuk tetap bisa bertahan dalam menghadapi persaingan. Membangun E-CRM merupakan sebuah kebutuhan untuk menjaga loyalitas pelanggan terhadap barang yang dijual pada Toko Multi Sport. Pengembangan CRM berbasis web dimaksudkan agar dapat memberikan kemudahan kepada pelanggan tetap maupun masyarakat luas dalam mendapatkan informasi barang dan dalam kegiatan memesan barang.

\section{METODE PENELITIAN}

Penelitian berbentuk studi kasus sedangkan metode penelitian yang digunakan adalah metode penelitian dan pengembangan atau yang lebih dikenal dengan Research and Development (R\&D). Kebutuhan dalam perancangan E-CRM menggunakan model sekuensial linear dengan pendekatan Waterfall. Metode ini merupakan model klasik yang bersifat sistematis dan mudah dipahami karena berurutan dalam tahapan membangun software mulai dari proses communication, planning, modeling, construction hingga proses deveplopment[10]. Teknik pengumpulan data menggunakan wawancara, observasi dan mempelajari semua dokumen penjualan selama ini.

\section{HASIL DAN PEMBAHASAN}

Sebagai toko yang bergerak dibidang penjualan peralatan olah raga, Toko Multi Sport berkeinginan untuk tetap menjaga agar pelanggannya selalu membeli peralatan olah raga di toko tersebut dan tidak pindah kepada pesaing. Toko Multi Sport menyadari pelayanan yang selama ini dilakukan hanya bersifat konvensional dimana pihak toko hanya menunggu pelanggan datang langsung ke toko dan memilih barang yang diinginkan. Kondisi ini membuat pelanggan kurang tertarik apalagi jika tidak mendapatkan barang yang dicari. Permasalahan ini bisa menjadi alasan pelanggan dapat berpindah ke toko yang lain demi mendapatkan apa yang diinginkan. Toko Multi Sport baru mendapatkan inovasi dan inovasi tersebut lebih cendrung kepada bagaimana cara agar pelanggan tetap loyal terhadap toko sehingga pihak mendapatkan keuntungan dari loyalitas pelanggan. Untuk mencapai keinginan tersebut maka pihak toko membangun sebuah sistem E-CRM berbasis web. Seperti dalam arsitektur tradisional, fokusnya adalah benar pada pengguna dan kebutuhan pengguna. Hal ini memerlukan perhatian khusus pada konten web, rencana bisnis, 
kegunaan, desain interaksi, informasi dan desain arsitektur web. Untuk optimasi mesin pencari yang efektif perlu memiliki apresiasi tentang bagaimana sebuah situs Web terkait dengan World Wide Web. Model arsitektur ini mendeskripsikan rancangan dari perangkat lunak disisi web server dan komputer client. Web server menggunakan apache, script PHP dan database MySQL. Perancanagan sistem mengindentifikasikan semua struktur sistem, prinsip komponen (sub-sistem/modul), hubungannya dan bagaimana didistribusikan. Arsitektur pengembangan sistem informasi Electronic Customer Relationship Management (E-CRM) yang diusulkan diperlihatkan pada gambar 1.
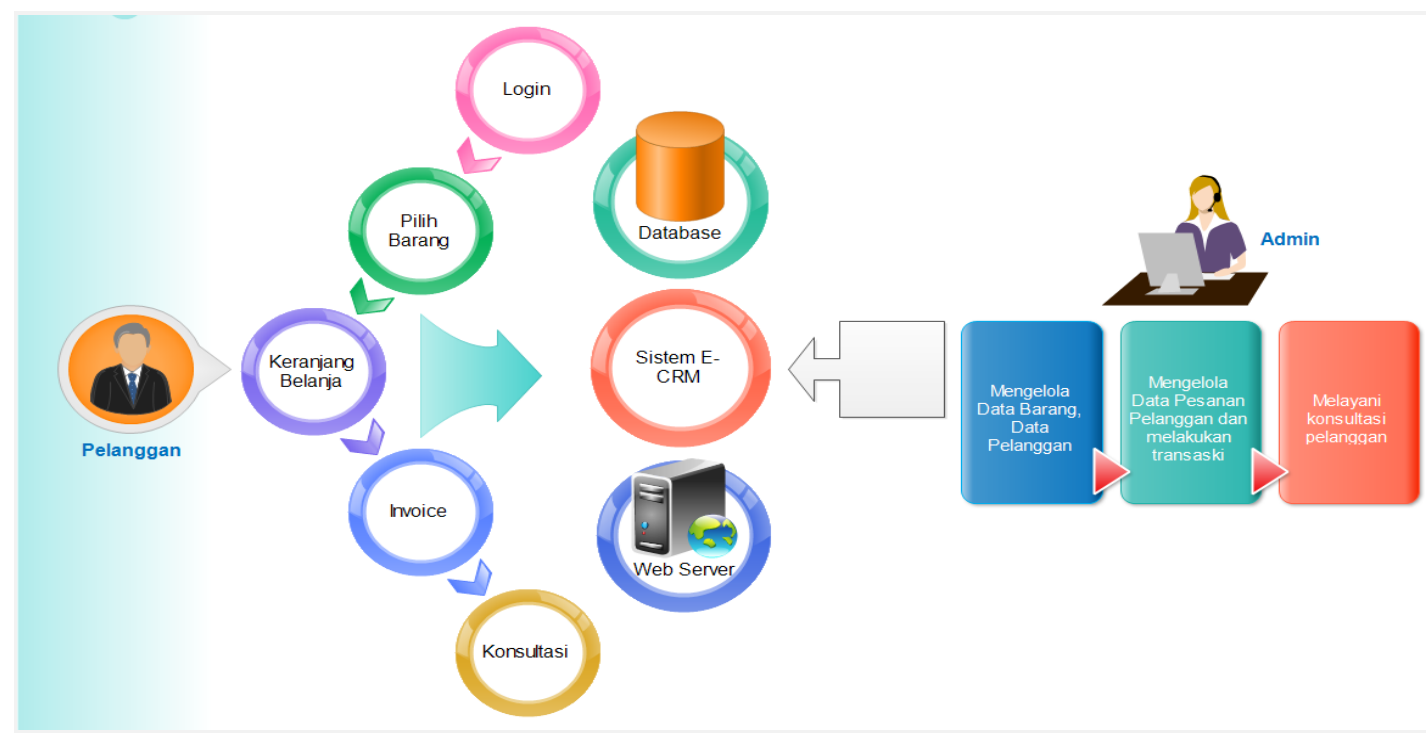

Gambar 1 Arsitektur E-CRM Toko Multi Sport Pontianak

Strategi dalam tahapan perancangan E-CRM mengacu pada perancangan berbasis obyek. Startegi ini dalam istilah aslinya disebut sebagai OOD (Object Orianted Design) dan dianggap menjadi strategi perancanaan paling modern. Dalam penelitian ini penulis menggunakan UML (Unified Modeling Language). Use case diagram pengelolaan konten E-CRM barang pada Toko Multi Sport terdiri dari admin dan pelanggan. Actor admin bertugas untuk memanajemen isi dari E-CRM secara keseluruhan sedangkan actor pelanggan memanajemen isi dari profil sendiri, memilih barang, memesan barang dan melakukan konsultasi dengan admin (lihat gambar 2).

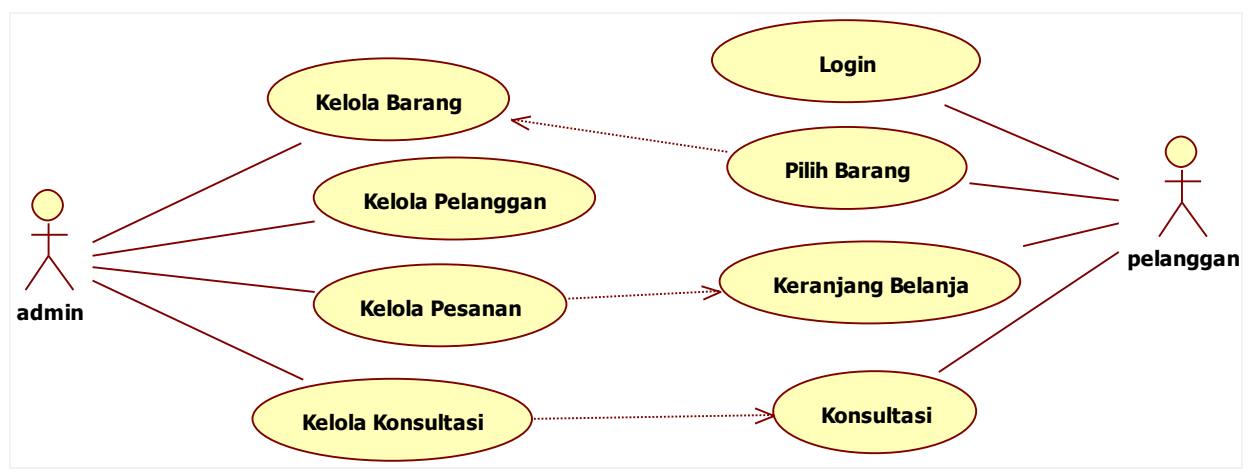

Gambar 2 Use case diagram E-CRM Toko Multi Sport Pontianak

Activity diagram menggambarkan proses paralel yang mungkin terjadi pada beberapa eksekusi. Activity diagram merupakan state diagram khusus, di mana sebagian besar state adalah action dan sebagian besar transisi di-trigger oleh selesainya state sebelumnya (internal processing). 
a. Pemesanan barang dimulai dari konsumen dengan memilih barang. Sistem menampilkan data barang secara detil. Pada tampilan detil data barang, konsumen bisa melakukan proses order dengan cara mengklik tombol order. Setelah tombol order diklik maka data barang yang diorder akan masuk ke dalam database. Setelah data masuk, maka konsumen dapat mencetak bukti order dan sistem akan mencetak bukti order tersebut. Admin melakukan membuka daftar order dan sistem menampilan form daftar order. Pada form data order, admin melakukan pengecekan terhadap data dan sistem akan memvalidasinya (lihat gambar 3).

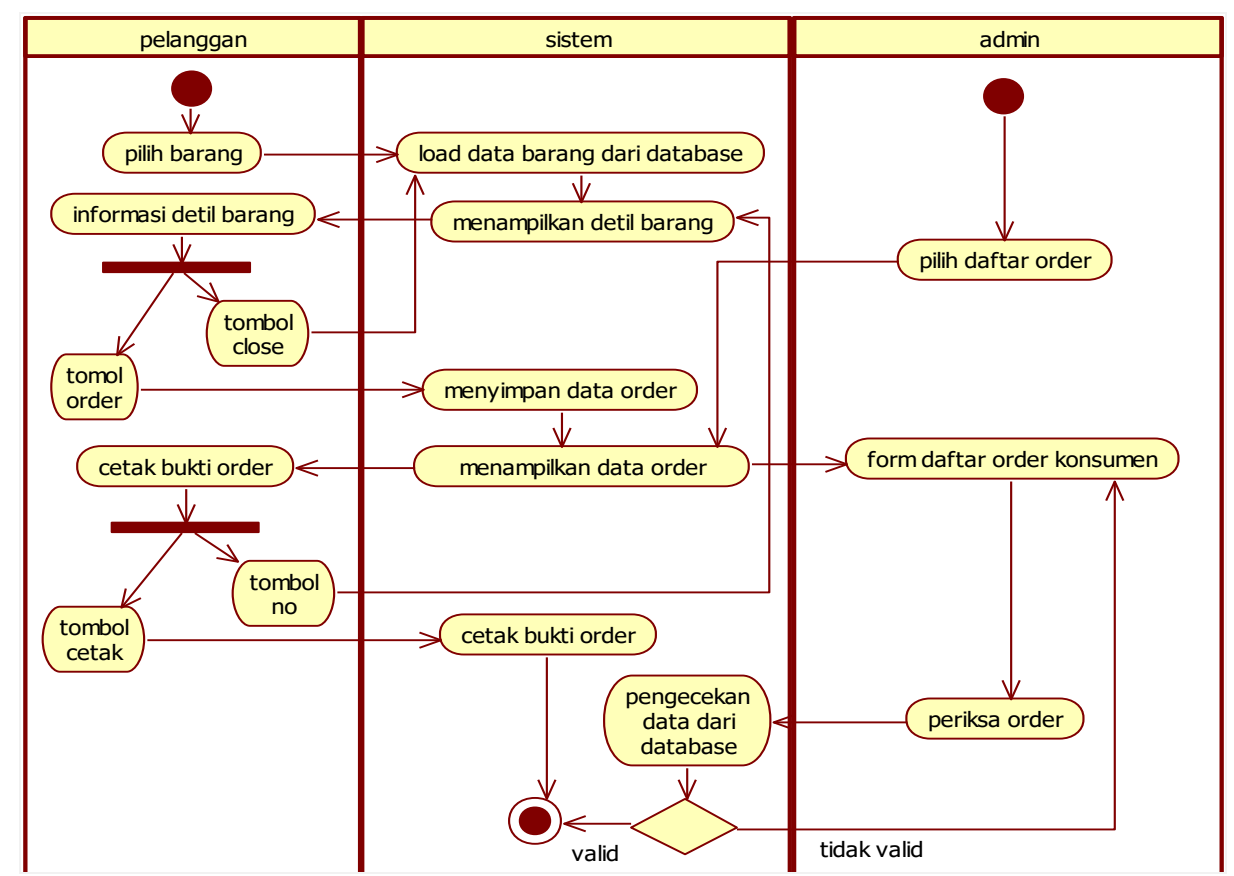

Gambar 3 Activity diagram Order Barang Toko Multi Sport Pontianak

b. Activity diagram kelola pembayaran dipergunakan untuk memberikan gambaran tentang aktivitas perusahaan dalam hal melakukan pengelolaan terhadap data pembayaran konsumen. Pada form ini perusahaan dapat melakukan proses terhadap data pembayaran yang dimulai dengan admin menampilkan daftar pembayaran, mencari pembayaran dan memproses data pembayaran(lihat gambar 4).

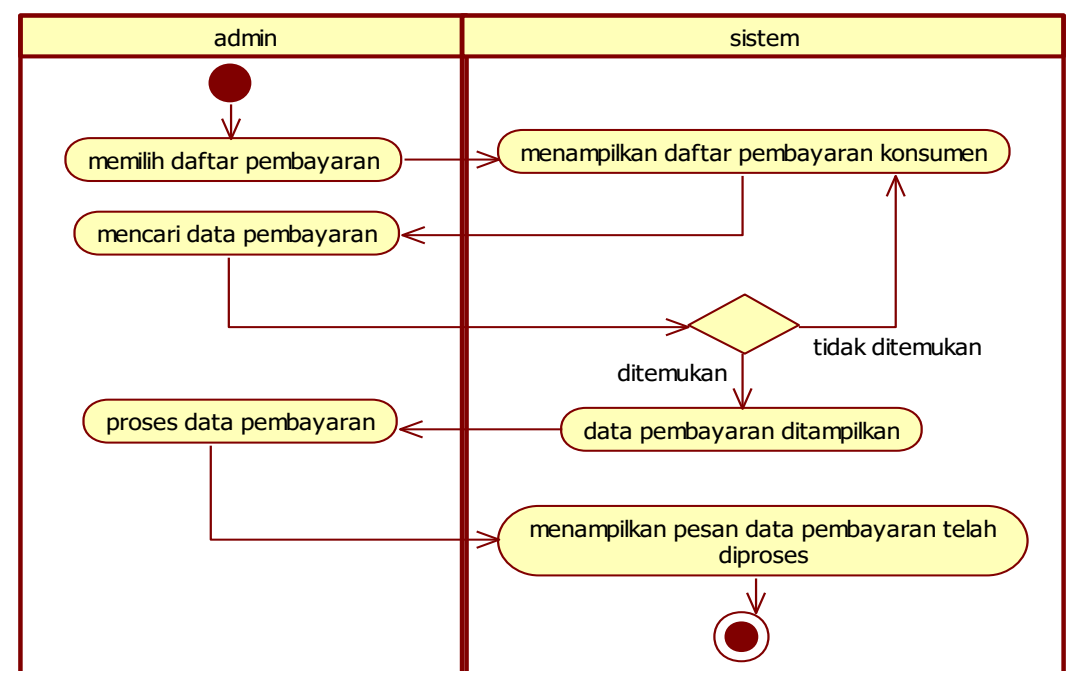

Gambar 4 Activity diagram Pembayaran Toko Multi Sport Pontianak 
c. Sequence diagram menggambarkan interaksi antar objek di dalam dan di sekitar sistem (termasuk pengguna, display, dan sebagainya) berupa message yang digambarkan terhadap waktu. Sequence diagram terdiri atar dimensi vertikal (waktu) dan dimensi horizontal (objekobjek yang terkait). Sequence diagram dapat digunakan untuk menggambarkan skenario atau rangkaian langkah-langkah yang dilakukan sebagai respons dari sebuah event untuk menghasilkan output tertentu. Diawali dari apa yang men-trigger aktivitas tersebut, proses dan perubahan apa saja yang terjadi secara internal dan output apa yang dihasilkan. Masing-masing objek, termasuk aktor, memiliki lifeline vertikal. Message digambarkan sebagai garis berpanah dari satu objek ke objek lainnya.

1. Sequence diagram order barang

Sequence diagram order barang memperlihatkan bagaimana seorang pelanggan berinteraksi langsung dengan sistem. Ketika pelanggan melakukan proses submit dari data yang telah diisikan, maka sistem akan melakukan control terhadap data yang telah diinputkan. Messages error akan ditampilkan apabila ada kesalahan pada data isian dan message sukses akan ditampilkan apabila data yang diinputkan benar. Data yang telah diinputkan dan yang telah disubmit akan langsung terkoneksikan dengan database member dan akan dilakukan proses penyimpanan data pesanan barang (gambar 5).

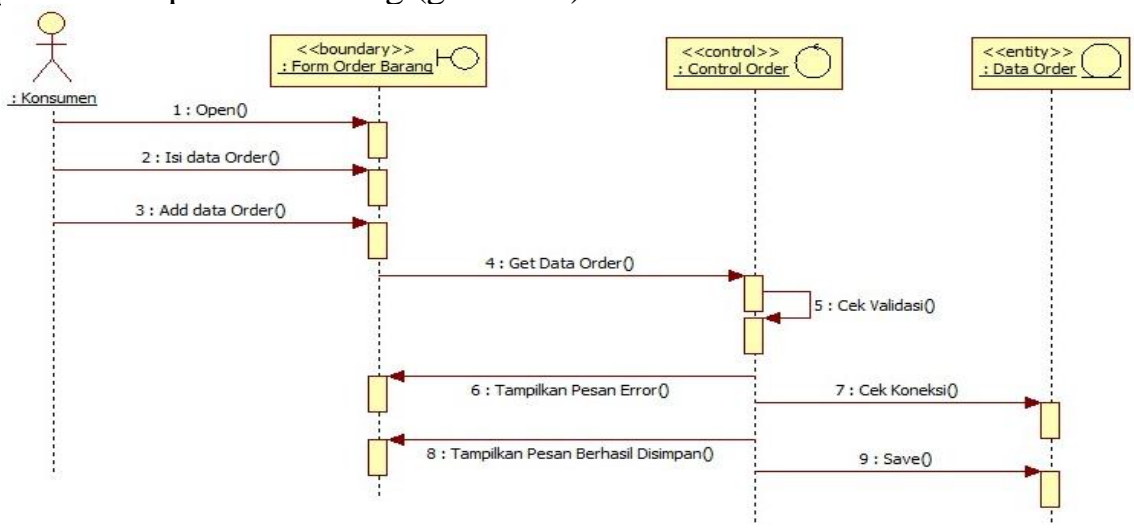

Gambar 5 Sequence diagram Order Barang

2. Sequence diagram kelola pembayaran

Sequence diagram kelola pembayaran memperlihatkan bagaimana seorang admin berinteraksi langsung dengan sistem. Ketika admin melakukan submit untuk menampilkan data pembayaran pelanggan, maka sistem akan melakukan control terhadap data yang ditampilkan. Messages error akan ditampilkan apabila ada kesalahan pada data isian dan message sukses akan ditampilkan apabila data yang diinputkan benar. Data yang telah diinputkan dan yang telah disubmit akan langsung terkoneksikan dengan database pembayaran dan akan dilakukan proses update status pembayaran. Berikut ini adalah gambar Sequence diagram kelola pembayaran (lihat gambar 6):

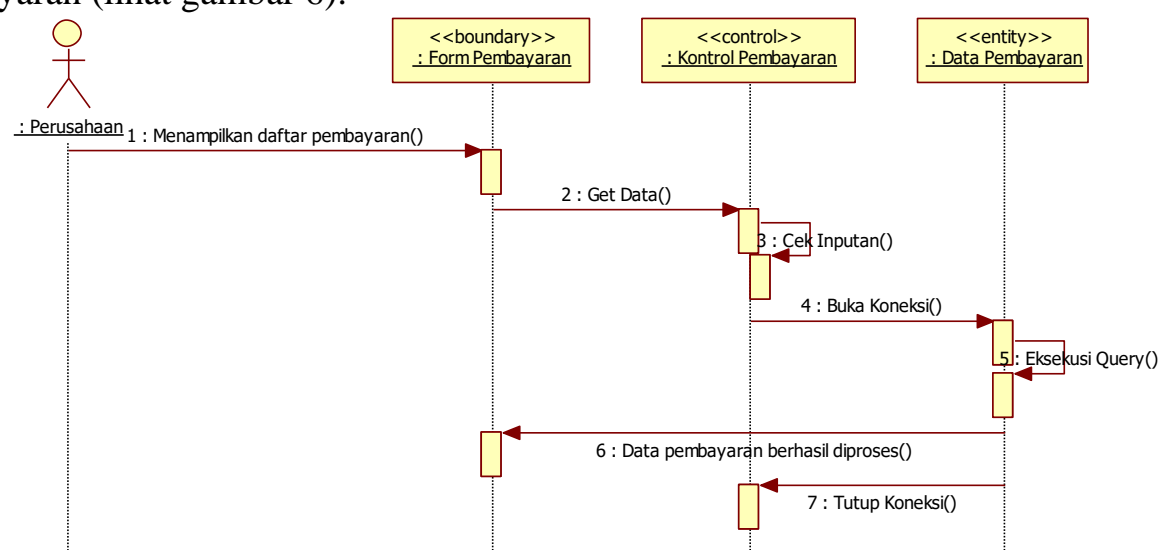

Gambar 6 Sequence diagram Kelola Pembayaran 
d. Class diagram adalah diagam yang digunakan untuk menampilkan beberapa kelas serta paketpaket yang ada dalam sistem/perangkat lunak yang sedang kita gunakan. Class diagram juga memberikan gambaran (diagram statis) tentang sistem/perangkat lunak dan relas-relasi yang ada didalamnya. Pada kelas diagram ini terdiri dari 6 (enam) yang masing-masing entitas saling ketergantungan antara yang satu dengan yang lainnya (lihat gambar 7).

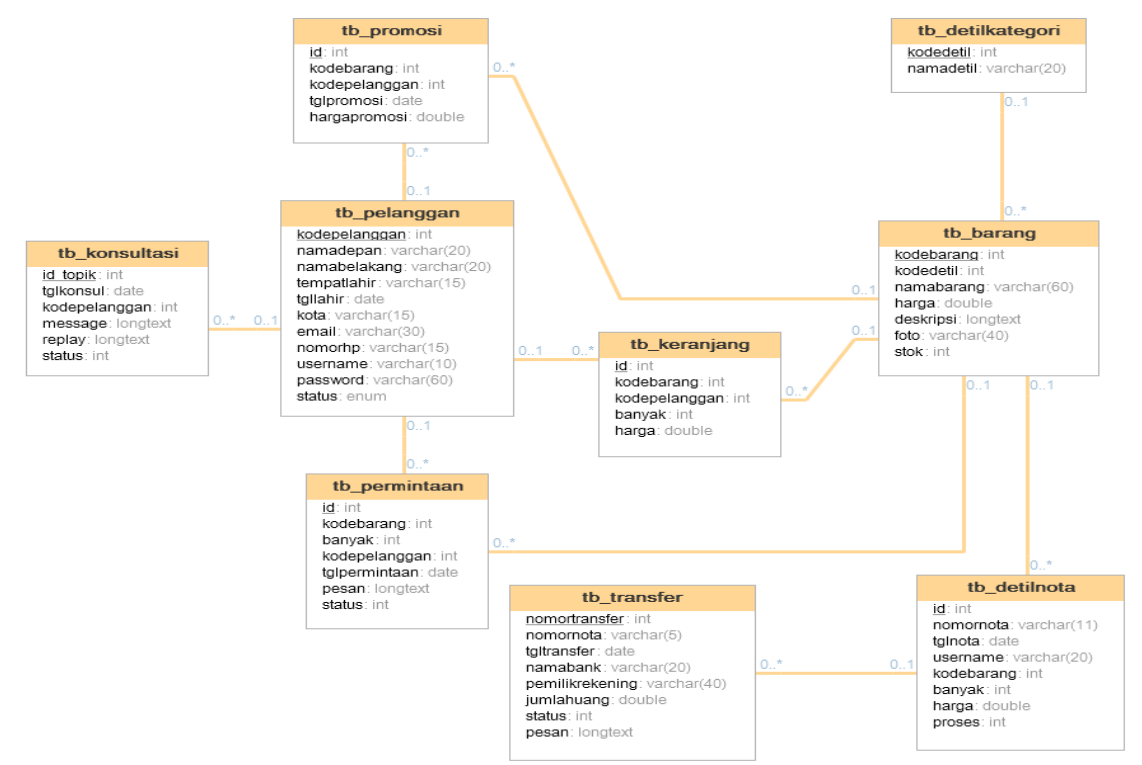

Gambar 7 Class diagram E-CRM Toko Multi Sport Pontianak

Mendesain sistem data terstruktur dan bagaimana dapat di representasikan ke dalam database. Arsitektur data digambarkan kedalam bentuk kamus data, spesifikasi tabel, diagram hubungan entitas dan normalisasi. Perancangan model konseptual perlu dilakukan disamping perancangan secara phisik. Pada perancangan konseptual, digunakan beberapa konsep pendekatan relasional namun tidak berarti konsep ini harus diimplementasikan ke model relasional saja tetapi juga apat dengan model hirarchi dan model network. Model konseptual mengkombinasikan beberapa cara untuk memproses data dan untuk beberapa aplikasi. Model konseptual tidak tergantung aplikasi tertentu dan tidak tergantung DBMS, hardware yang digunakan. Pada perancangan model konseptual tinjauan dilakukan pada struktur data dan relasi antar file menggunakan model dan relasional.

Sehubungan dengan perancangan E-CRM yang difokuskan pada rancangan sistem usulan ini maka dalam pembuatan kamus data didasarkan pada struktur dari tabel database. Kamus data digunakan untuk membantu para pemakai mengerti mengenai aplikasi yang akan dikembangkan secara terinci dan mengorganisasikan semua elemen data yang terkait serta tidak mengalami kesulitan dalam memahami pemodelan sistem yang dikembangkan secara logika.

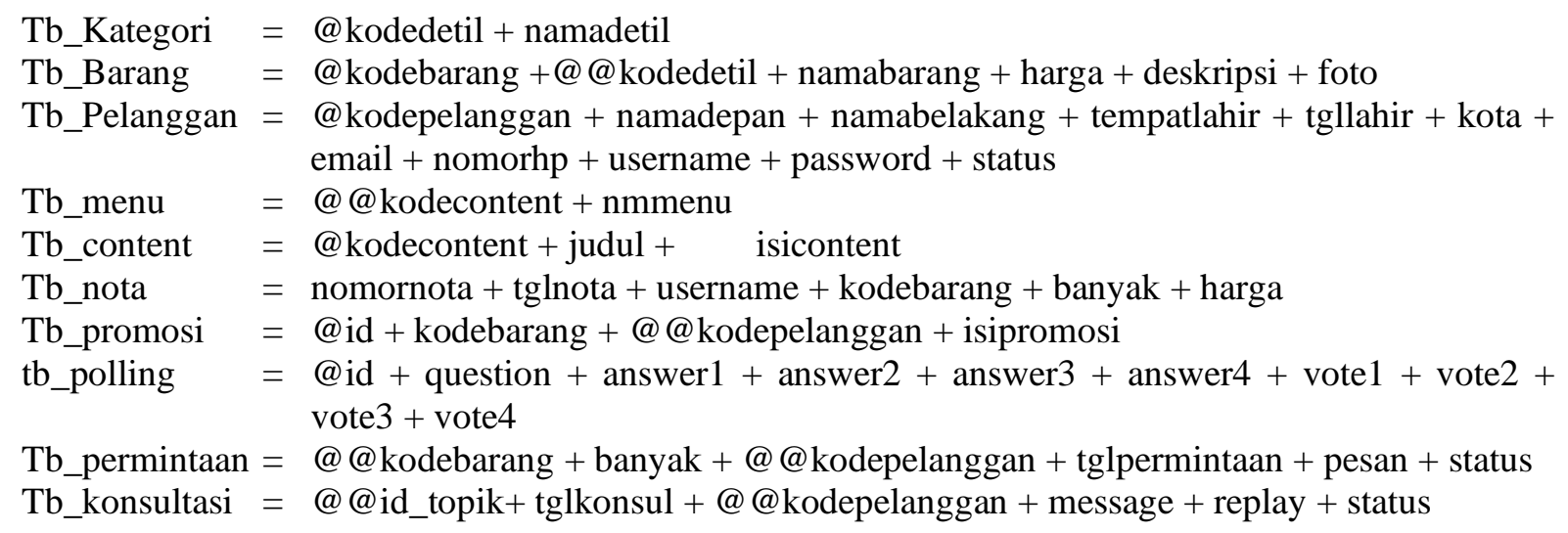


Table kategori terdiri dari satu field yang berlaku sebagai primary key yaitu kodedetil yang merupakan nomor unik yang dimiliki oleh setiap kategori barang. Table barang terdiri dari satu field yang berlaku sebagai primary key yaitu kodebarang yang merupakan nomor unik yang dimiliki oleh setiap barang dan satu field sebagai foreign key yaitu kodedetil. Table pelanggan terdiri dari satu field yang berlaku sebagai primary key yaitu kodepelanggan. Tabel nota terdiri dari satu field sebagai primary yaitu nomornota dan satu field sebagai foreign key yaitu kodebarang yang dipergunakan sebagai penghubung antara tabel barang dan tabel nota. Tabel permintaan dipergunakan untuk menyimpan data permintaan barang oleh pelanggan yang terdari dari dua field foreign key yaitu kodebarang dan kode pelanggan. Field kodebarang dipergunakan untuk merelasikan ke dalam tabel barang dan field kodepelanggan sebagai relasi ke tabel pelanggan.

Diagram hubungan entitas adalah suatu dokumentasi data dengan mengidentifikasi entiti data dan memperhatikan hubungan yang ada diantara entiti tersebut. Sistem informasi E-CRM adalah sebuah sistem yang dapat dipergunakan untuk mempromosikan barang, berkomunikasi dengan konsumen dan melakukan transkasi secara online ke konsumen (lihat gambar 8):

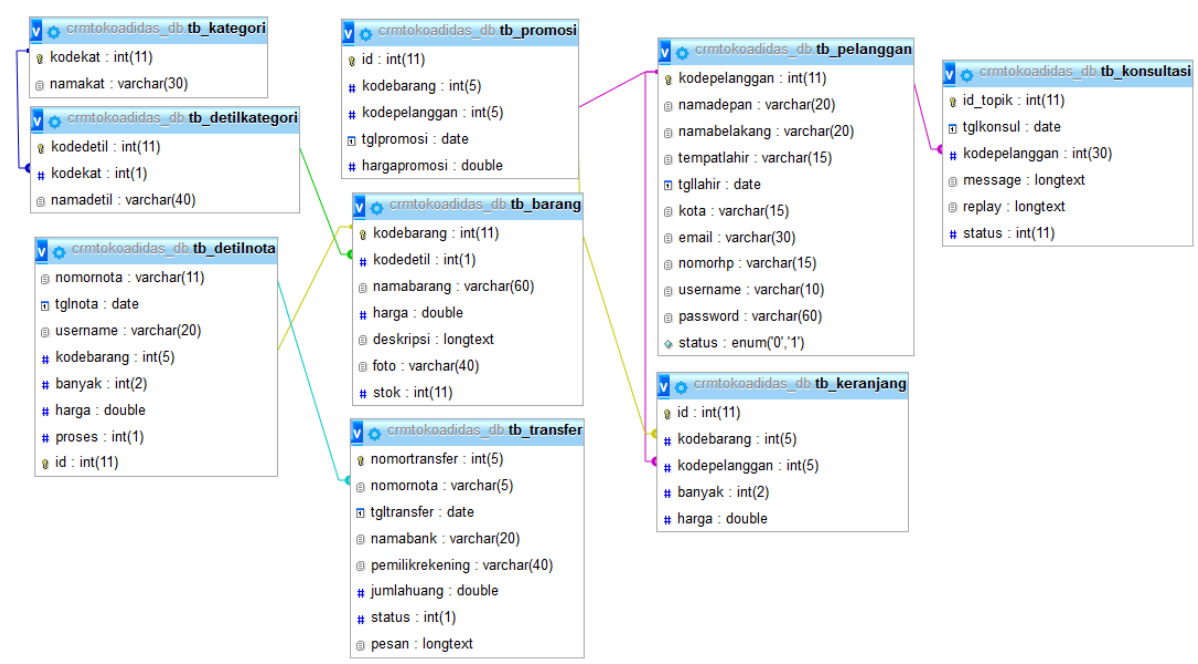

Gambar 8 Diagram Hubungan Entitas

Contruction merupakan kegiatan melakukan desain bentuk yang dapat dimengerti oleh mesin, yaitu ke dalam bahasa pemrograman melalui proses coding. Tahap ini merupakan implementasi dari tahap design yang secara teknis dikerjakan oleh programmer. Kemudian setelah tahap coding selesai, semua fungsi-fungsi software diujicobakan agar software bebas dari error dan hasilnya harus benarbenar sesuai dengan kebutuhan yang sudah didefinisikan sebelumnya. Dalam pengimplementasian sistem yang dibuat, penulis menggunakan bahasa pemograman PHP (PHP: Hypertext Prepocessor) dan sistem database yang dipakai adalah MySQL. MySQL adalah sebuah implementasi dari sistem manajemen basis data relasional (RDBMS) yang didistribusikan secara gratis dibawah lisensi GPL (General Public License).

a. Rancangan halaman utama ini adalah gambaran dari bentuk E-CRM secara umum. Dimana pada rancangan ini dibagi menjadi beberapa bagian yaitu bagian header, bagian footer, bagian menu atas, bagian menu kiri dan bagian tengah. Berikut ini adalah rancangan halaman utama E-CRM (lihat gambar 9): 


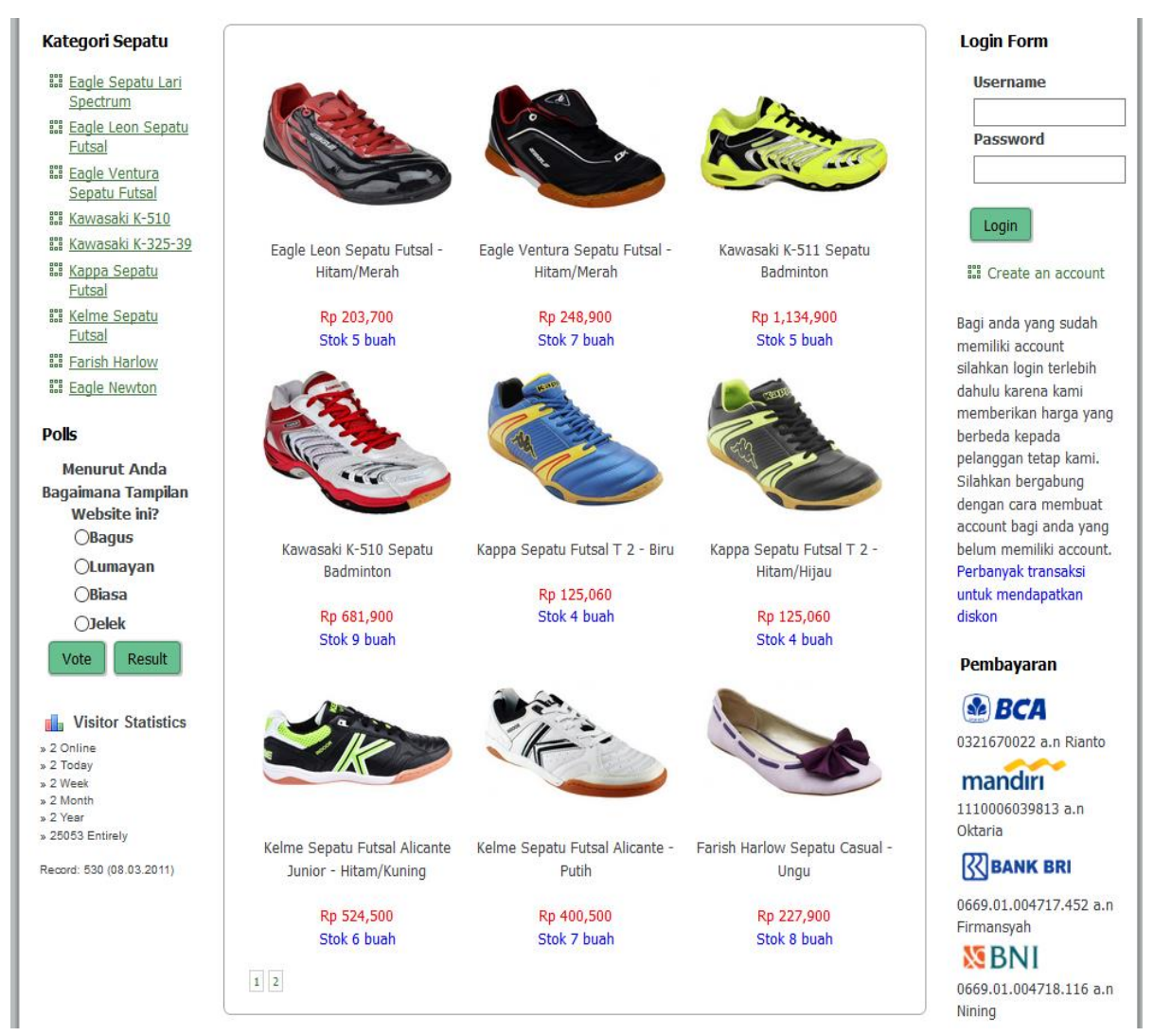

Gambar 9 Halaman Utama E-CRM Toko Multi Sport Pontanak

b. Konstruksi Form Detil Barang

Form detil barang adalah form yang dipergunakan untuk menampilkan informasi barang secara detil dan pada form ini pelanggan dapat melakukan pemesanan barang dengan cara mengisikan jumlah barang yang dibeli dan melakukan submit terhadap tombol order (gambar 10).

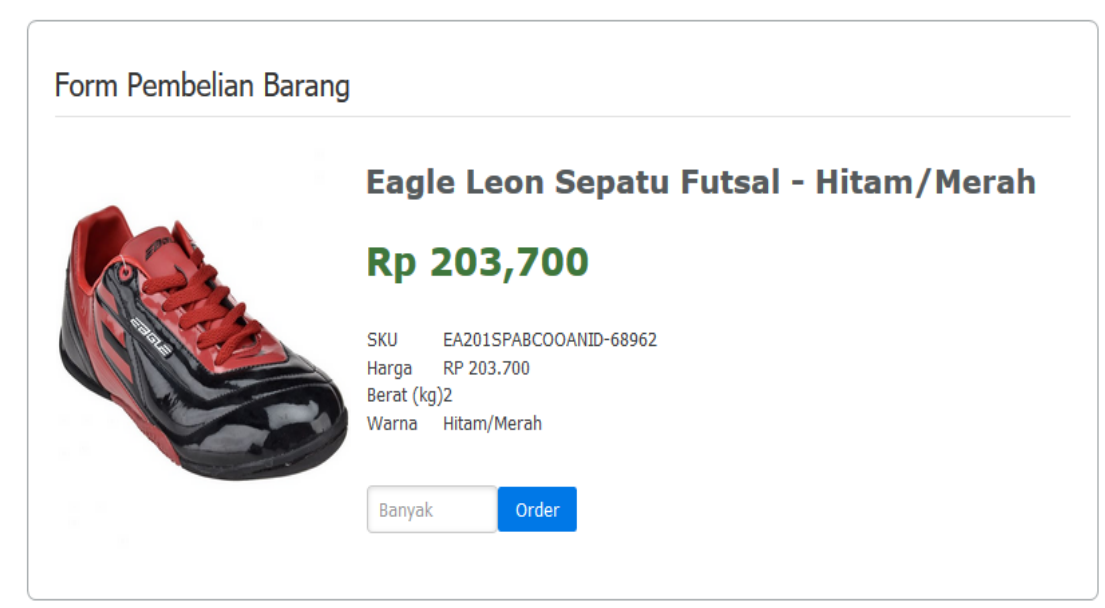

Gambar 10 Form Detil Barang E-CRM Toko Multi Sport Pontianak

c. Konstruksi Form Histori Pembelian Barang

Form histori pembelian barang dipergunakan oleh pelanggan untuk menampilkan daftar barang yang telah dipesan sebelum diproses oleh admin. Selama data barang masih tampil pada form ini maka data barang tersebut belum diproses oleh admin dan pelanggan dapat melakukan pembatalan pembelian dengan cara menghapus data tersebut (gambar 11). 


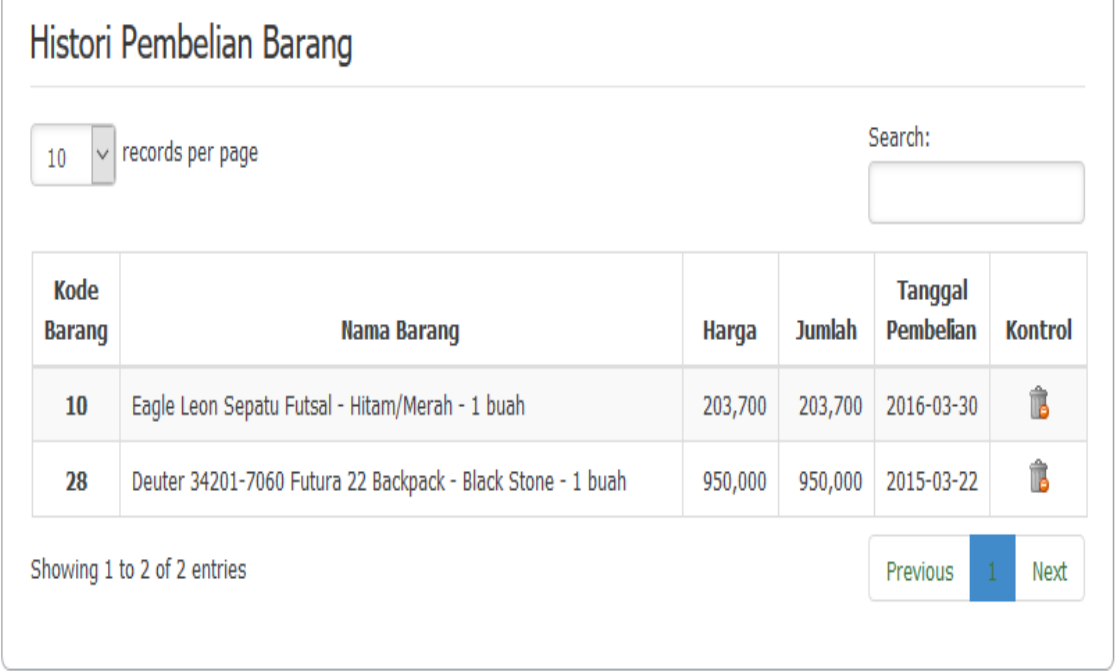

Gambar 11 Form Histori Pembelian Barang E-CRM Toko Multi Sport Pontianak

d. Konstruksi Form Diskusi

Form diskusi diperlukan bagi pelanggan untuk berkomunikasi dengan pemilik toko terkait dengan informasi barang secara up-to-date. Dengan form ini admin dapat membaca apa yang menjadi kebutuhan dari setiap pelanggan dan selanjutnya akan ditindaklanjuti sesuai dengan kebijakan pemilik toko (lihat gambar 12).

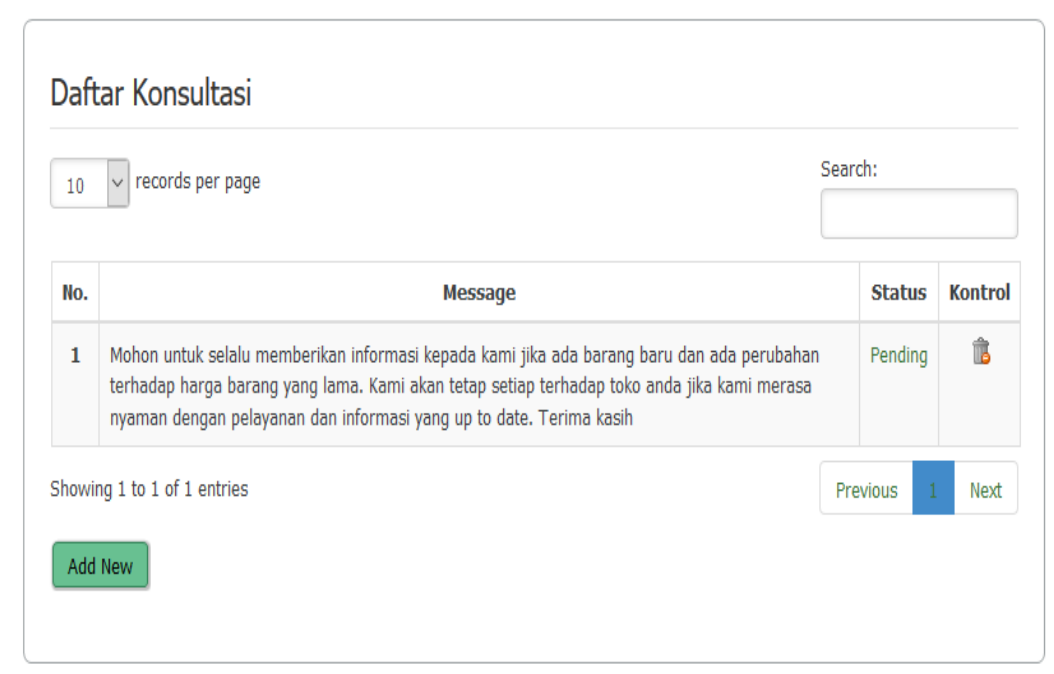

Gambar 12 Konstruksi Form Diskusi

e. Konstruksi Form Data Konsultasi

Form data konsultasi adalah sebuah form milik admin yang dipergunakan oleh admin untuk melihat pesan dari pelanggan dan selanjutkan admin membalas pesan dari pelanggan dengan cara mengklik baris pesan tersebut. Jika status dari pesan adalah pending itu artinya admin belum melakukan balasan dari pesan tersebut (lihat gambar 13). 


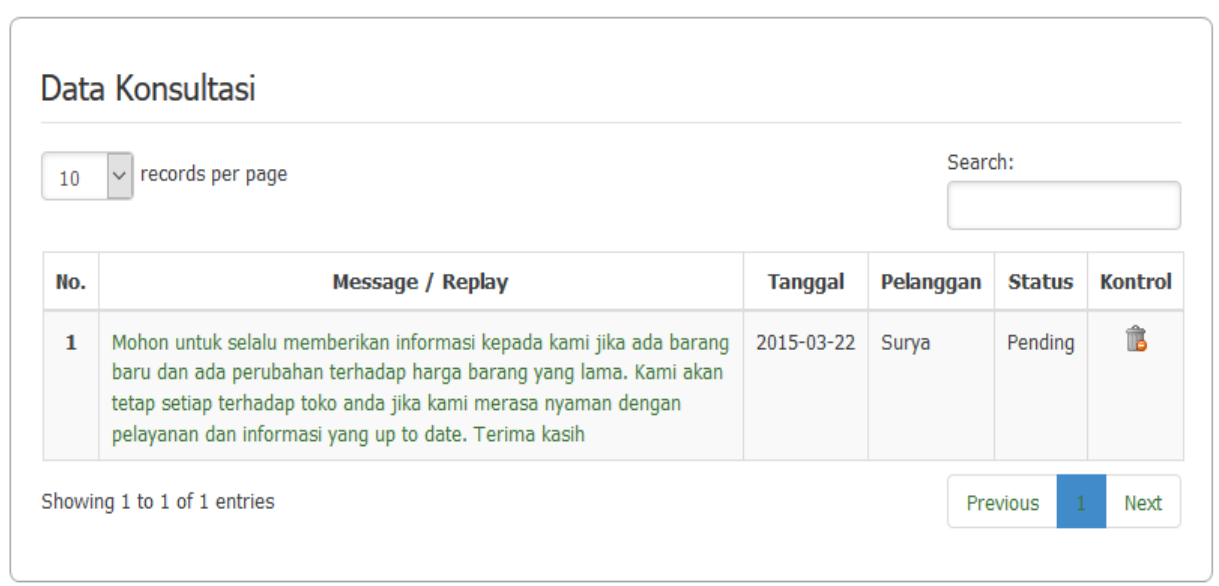

Gambar 13 Konstruksi Form Data Konsultasi

Tahap penyebaran (deployment) adalah tahap dimana sistem dibuat tersedia bagi komunitas pengguna. Tergantung pada komunitas pengguna, ini mungkin memerlukan tambahan sumber daya teknologi informasi. Proses penyebaran harus direncanakan dengan baik sehingga meminimalkan downtime dan dampak untuk mengakhiri produktivitas pengguna. Registrasi domain memerlukan waktu kurang lebih 24 jam terhitung dari mulai registrasi domain. Setelah domain dinyatakan aktif, maka semua file web perlu diuploadkan ke hosting yang telah aktif. Proses pengiriman file web ke server merupakan sebuah proses tranfer seluruh file web yang ada di locahost ke web server. Setelah dilakukan upload, maka perlu dilakukan perubahan konfigurasi database dan penyesuaian koneksi.

\section{KESIMPULAN}

Setelah dilakukan perancangan sesuai dengan metodologi yang dipergunakan dan sudah melalui tahap uji coba sistem, maka Toko Multi Sport dapat menggunakan sistem informasi pemesanan berbasis website untuk menjual barang secara online. Perancangan website pemesanan yang berbasiskan konsep E-CRM telah membantu pemilik toko untuk mengikat pelanggan dengan memberikan fasilitas promosi dan informasi up-to-date barang baru maupun harga barang lama kepada pelanggan tertentu. Adanya konsep E-CRM memberikan kemudahan bagi pelanggan untuk melakukan pemesanan barang serta pelanggan dapat berkonsultasi dengan pemilik toko terkait dengan harapan dan keinginan pelanggan sehingga menciptakan loyalitas yang tinggi bagi pelanggan.

\section{SARAN}

Website sistem informasi pemesanan berbasis E-CRM yang telah dibangun sudah dapat menjadi peluang bagi Toko Multi Sport Pontianak untuk meningkatkan volume penjualan dengan menumbuhkan loyalitas pelanggan yang berkesinambungan. Namun masih perlu dikembangkan secara berkelanjutan dengan penambahan fasilitas baru dan bisa dirancang khusus untuk pengguna mobile. E-CRM yang bisa diakses dengan menggunakan mobile sangat bermanfaat karena perangkat mobile seperti tablet mudah dipergunakan dan memiliki koneksi internet dengan mempergunakan mobile data.

\section{DAFTAR PUSTAKA}

[1]Djati, S. P., \& Darmawan, D. (2005). Pengaruh kinerja karyawan terhadap kepuasan, kepercayaan, dan kesetiaan pelanggan. Jurnal Manajemen dan Kewirausahaan (Journal of Management and Entrepreneurship), 7(1), pp-48.

[2] Ferrinadewi, E., \& Djati, S. P. (2004). Upaya Mencapai Loyalitas Konsumen dalam Perspektif Sumber Daya Manusia. Jurnal Manajemen dan Kewirausahaan (Journal of Management and Entrepreneurship), 6(1), pp-15.

[3] Semuel, H. (2006). Ekspektasi Pelanggan dan Aplikasi Bauran Pemasaran Terhadap Loyalitas Toko Moderen Dengan Kepuasan Pelanggan Sebagai Intervening Studi Kasus pada Hypermarket Carrefour di Surabaya. Jurnal Manajemen Pemasaran, 1(2). 
[4] Yunitarini, R., Santoso, P. B., \& Nurwarsito, H. (2013). Implementasi Perangkat Lunak Electronic Customer Relationship Management (E-CRM) dengan Metode Framework of Dynamic CRM. Jurnal EECCIS, 6(1), pp-83.

[5] Nelly, N., Hudiarto, H., \& Yudhika, R. (2009). Perancangan E-Customer Relationship Management Pada PT. Starsindo Logistics. Communication and Information Technology Journal, $3(2)$.

[6] Afrina, M., \& Ibrahim, A. (2014). Rancang Bangun Electronic Costumer Relationship Management (e-crm) Sebagai Sistem Informasi Dalam Peningkatan Layanan Perpustakaan Digital Fakultas Ilmu Komputer Unsri. Jurnal Sistem Informasi, 5(2).

[7] Putra, D. R. S. (2013). Analisis dan Rancang Bangun Aplikasi Electronic Customer Relationship Management Untuk Tour And Travel Di Indonesia (Studi Kasus: Cahaya Community Tour And Travel) (Doctoral dissertation, UAJY).

[8] Oetomo, B. S. D., Simandjuntak, J. P., \& Andreas Ari Sukoco, M. M. (2003). i-CRM Membina Relasi dengan Pelanggan. Com. Penerbit Andi.

[9] King, D., \& Lee, J. (2000). Electronic commerce: a managerial perspective (Vol. 1). Upper Saddle River, NJ: Prentice Hall.

[10] Pressman, roger S. 2010. Software Engineering: A Practicioner's Approach, 7th Edition. McGraw-Hill Inc., New York. 